\title{
Microstrip Antenna using DGS for Satellite Communication
}

\author{
Anurag Garg \\ SPS University \\ Udaipur \\ India
}

\author{
Amrit Ghosh, PhD \\ SPS University \\ Udaipur \\ India
}

\author{
Prasun Chakrabarti, PhD \\ SPS University \\ Udaipur \\ India
}

\begin{abstract}
In this paper, authors proposed a new design of DGS to improve the characteristics of microstrip antenna for the use of satellite communication using $\mathrm{L}$ band frequencies for communication. This proposed antenna is designed at $1.78 \mathrm{GHz}$ (L Band). To achieve a very important bandwidth and efficiency enhancement author proposed symmetrical parallel plates shaped DGS in the ground plane. This symmetrical DGS on the other side of the patch increases the fringing field which consequently increased the parasitic capacitance. This coupling of patch and ground made the bandwidth and directivity enhanced from the RMPA without DGS.
\end{abstract}

\section{General Terms}

DGS (Defected Ground Structure), Simulation of Antenna, CST-MWS.

\section{Keywords}

Microstrip antenna, return loss, efficiency, bandwidth.

\section{INTRODUCTION}

Antenna is basically defined as a transducer, which works as a part of a transmitting or receiving system designed to radiate or to receive electromagnetic waves. Application of a conventional antenna always limited since they are governed by the 'right hand rule' which determine how electromagnetic wave should behave. Many theories were presented over rectangular microstrip patch antenna and for their parameter improvement. Some of them were use of parasitic elements [1], different feeding techniques [2], metamaterial incorporation [3], and one of the major setback was use of defected ground structure technique [4], it is not only easy to design and cheap in fabrication as well. Not too much calculation required while going through this process.

In recent years various applications of microstrip antenna came into existence like microwave and wireless communication system. Therefore, microstrip antenna is very suitable to apply at various fields like satellite, military, medical application and telecommunication system [5]. Here in this paper authors are interested in studying the performance of a rectangular patch when DGS is introduced in the ground plane of the patch antenna.
This research was conducted on the frequency of $1.78 \mathrm{GHz}$ by designing a microstrip patch antenna and then a highly inspirational parameter improvement technique which is defected ground structure technique was used. After using DGS technique in patch antenna and applying a parallel plate shaped structure in ground plane, bandwidth has been improved and return loss too.

DGS is an etched symmetrical or non-symmetrical cascaded configuration defect in ground of a planar transmission line (e.g., microstrip, coplanar and conductor backed coplanar waveguide) which disturbs the shield current distribution in the ground plane cause of the defect in the ground.

\section{CALCULATION}

A new microstrip antenna has been proposed for the operating frequency of $1.78 \mathrm{GHz}$. Formulas listed in [6] were used while calculating dimensions for the patch antenna and then a microstrip patch antenna was designed in CST simulation software and the simulation result were analyzed. Designed antenna is shown in figure 1 and in subsequent figures results of the same designed antenna are listed.

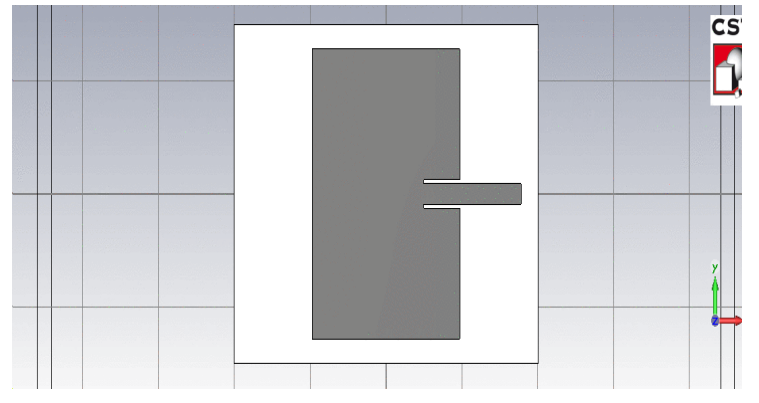

Fig. 1. Patch antenna at $2.2 \mathrm{GHz}$.

Table 1. Dimensions of patch

\begin{tabular}{|c|c|c|}
\hline S. No. & Parameters & Dimension $(\mathbf{m m})$ \\
\hline 1 & Length of patch & 38.8856 \\
\hline 2 & Width of patch & 51.1912 \\
\hline 3 & Length of feed & 35.5956 \\
\hline 4 & Width of feed & 3.6 \\
\hline
\end{tabular}




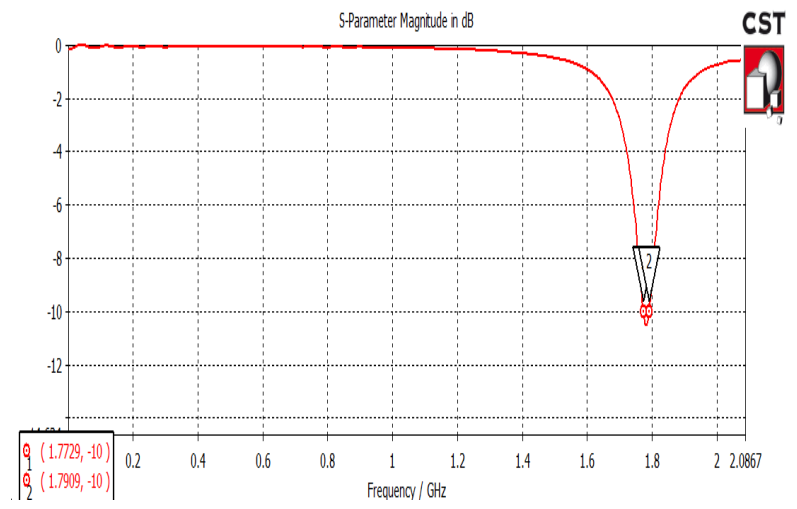

Fig. 2. Simulated result of RMPA shown in Fig. 1 with

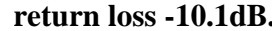

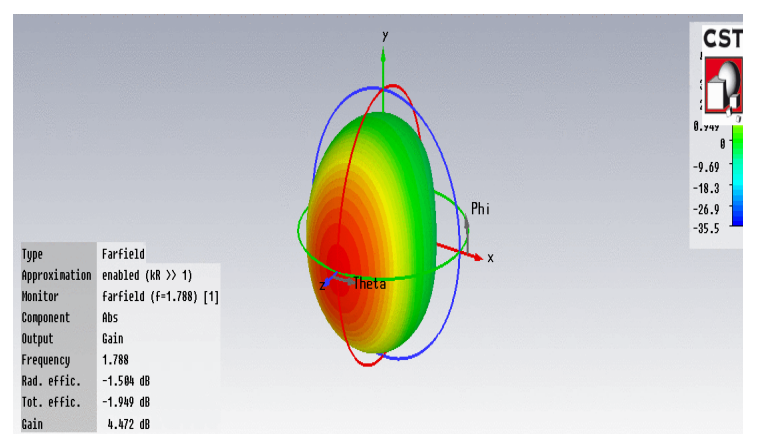

Fig. 3. Simulation result shows directivity, efficiency and radiation pattern.

Designed patch antenna using dimensions listed in table 1 was simulated using CST and its simulation results are shown in figure 1, 2 and 3 respectively. Simulated result shows return loss of $-11 \mathrm{~dB}$, bandwidth $23.5 \mathrm{MHz}$, gain of $4.472 \mathrm{dBi}$ whereas the efficiency was around $70 \%$. These parameters are not fulfilling the requirement of satellite communication viz. low return loss and high efficiency so parameter improvement is desirable. To fulfill demand DGS technique [7] was implemented, following is proposed DGS structure in figure 4 and corresponding figure shows simulated results after implementing defected ground structure on the ground plane of the patch [8].

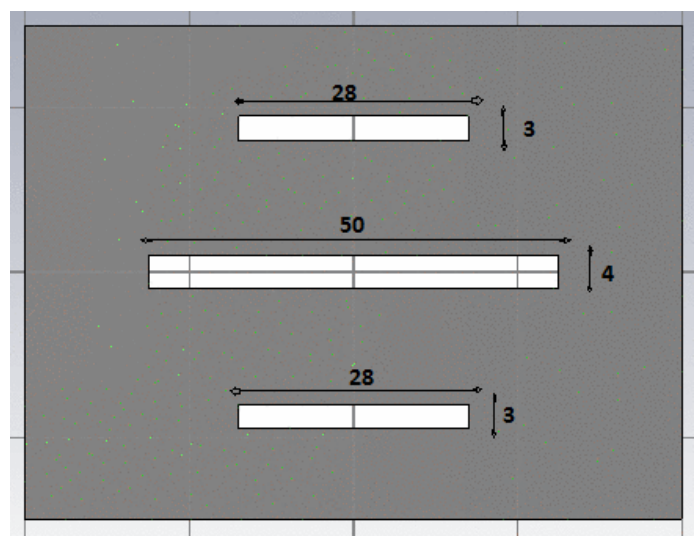

Fig. 4. Proposed DGS on the ground plane. (all dimensions are in $\mathbf{~ m m}$ )

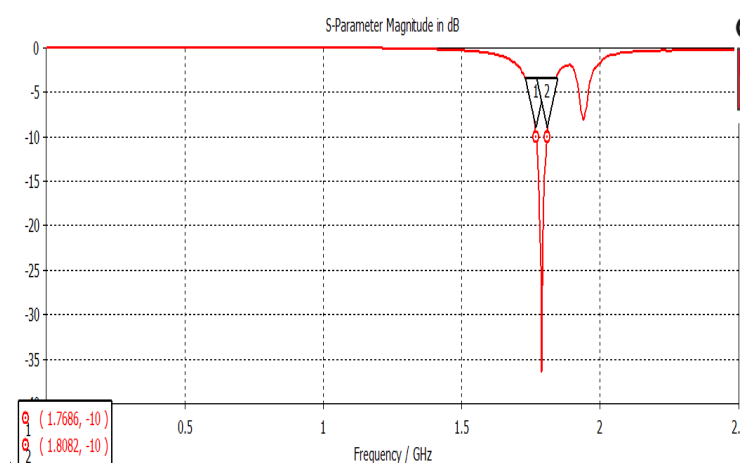

Fig. 5. This is the simulated result of design proposed on ground plane in figure 4, dip at $2.2 \mathrm{GHz}$.

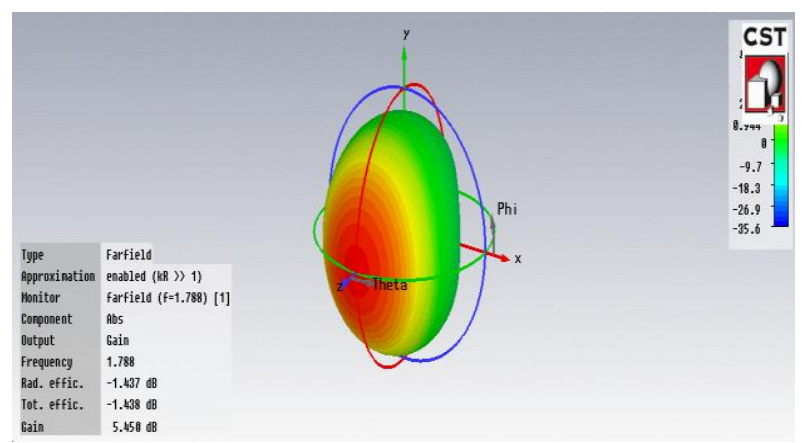

Fig. 6. This is the simulated result of design in figure 4, showing radiation pattern with efficiency and directivity.

The result shown in above figures 5 and 6 indicates the improvement after incorporation of DGS on the ground plane of the proposed patch. Detailed discussion and comparison is shown in table no. 2 .

\section{CALCULATION}

After comparing the results of patch antenna before and after implementing defected ground structure on the base of the patch, $t$ has been observed that there has been a tremendous improvement was achieved. And it was observed by comparing the results, following is the comparison table before and after DGS implementation. There is significant improvement achieved in Return loss, gain and bandwidth. Efficiency is merely gets affected. These results are compared w.r.t the parameter variation. Comparative chart is shown below in table 2 .

Table 2: Comparison Chart

\begin{tabular}{|c|c|c|c|}
\hline $\begin{array}{l}\text { S. } \\
\text { no. }\end{array}$ & Parameters & $\begin{array}{l}\text { Before DGS } \\
\text { introduction }\end{array}$ & After DGS introduction \\
\hline 1 & Return loss & $-10 \mathrm{~dB}$ & $-36 \mathrm{~dB}$ \\
\hline 2 & Bandwidth & $18 \mathrm{MHz}$ & $39.6 \mathrm{MHz}$ \\
\hline 3 & Gain & $4.462 \mathrm{~dB}$ & $5.450 \mathrm{~dB}$ \\
\hline 4 & Efficiency & $63 \%$ & $71.8 \%$ \\
\hline
\end{tabular}


After the comparison it has been observed that the proposed DGS structure ameliorate the parameters up to a great extent, the proposed DGS method improves the return loss and increased the bandwidth above two times the bandwidth of microstrip antenna alone.

\section{CONCLUSION}

This proposed microstrip patch antenna was designed for the applications of L band. Initially only microstrip patch antenna parameters was analyzed, it was found that parameters are not significantly fulfilling the requirement of the targeted application i.e. satellite communication for GPS applications but when a parallel plate shaped DGS is implemented in the opposite side of patch in ground plane, a significant improvement is achieved. Bandwidth and return loss was highly improved [9-11]. Bandwidth has been modified up to $100 \%$ and so was the return loss which has been modified above $300 \%$.

\section{REFERENCES}

[1] Jun-Won Kim, Tae-Hwan Jung, Hong-Kyun Ryu, JongMyung Woo, "Compact Multiband Microstrip Antenna Using Inverted L and T-Shaped Parasitic Elements." IEEE Antennas and Wireless Propagation Letters, vol. 12, 2013, pp. 1299-1302.

[2] Emad S. Ahmed "Multiband CPW-Fed Rectangular Ring Microstrip Antenna Design for Wireless Communications." IEEE Jordan Conference, AEECT, 2011.
[3] D. M. Pozar, "Introduction to microwave system" in Microwave Engineering, 4thEdition. John Wiley \& Sons 2004, pp. 658-99.

[4] Pradeep Paswan, Vivekanand Mishra, P. N. Patel, Surabhi Dwivedi "Performance Enhancement of Coaxial Feed Microstrip Patch Antenna Using Left-Handed Metamaterial Cover," IEEE conference, SCEECS, 2014.

[5] Rajeshwar Lal Dua, Himanshu Singh, Neha Gambhir "2.45 GHz Microstrip Patch Antenna with Defected Ground Structure for Bluetooth", IJSCE, Volume-1, Issue-6, January 2012, pp. 262-265

[6] C. A. Balanis, "Microstrip Antenna" in Antenna Theory and Design, Vol 3, John Wiley \& Sons, Inc., 1997, pp. 811-882.

[7] Zulkifli, Fitri Yuli, Eko Tjipto Rahardjo, and Djoko Hartanto. "Mutual coupling reduction using dumbbell defected ground structure for multiband microstrip antenna array." Progress In Electromagnetics Research Letters 13 (2010): 29-40.

[8] M. M. Bait-Suwailam and H. M. Al-Rizzo, "Size reduction of microstrip patch antennas using slotted Complementary Split-Ring Resonators," in Technological Advances in Electrical, Electronics and Computer Engineering (TAEECE), 2013 International Conference on, 2013, pp. 528-531.

[9] D. R. Jackson and N. G. Alex poulos, "Gain enhancement methods for printed circuit antennas," IEEE Trans, Antennas Propag, vol. AP-33, no. 9,Sep, 1985.

[10] H. Nakano, M. Ikeda, K. Hitosugi, and 1. Yamauchi, "A spiral antenna sandwiched by dielectric layers," IEEE Trans. Antennas Propag., vo1.52, no. 6,Jun. 2004,

[11] R. Waterhouse, "Small microstrip patch antenna," Electronics Letters, vol. 31, pp. 604-605, 1995 